\title{
Use of the Extreme Value Analysis in Determining Annual Probability of Exceedance for Bushfire Protection Design
}

\author{
GRAHAME DOUGLAS ${ }^{1}$, YAPING HE ${ }^{1}$, YANG XIANG $^{1}$ and E. CHARLES MORRIS ${ }^{2}$ \\ ${ }^{1}$ School of Computing, Engineering and Mathematics \\ ${ }^{2}$ School of Health and Science \\ University of Western Sydney \\ Locked Bag 1797, Penrith, NSW 2751, Australia.
}

\begin{abstract}
Historically extreme value analysis has been used to guide human activities against many forms of natural hazards such as floods, storms, heat waves and wind. However, it has not been used for extreme fire weather assessment. This may be because forest fire danger index is a composite of differing parameters which may not be regarded as being associated with adverse fire weather individually, however, collectively may result in Extreme fire weather conditions. This paper offers new insights in the use of the extreme value analysis for the McArthur Forest Fire Danger Index (FFDI) so as to provide a scientific basis for planning, development and building construction in bushfire prone areas. The underlying principle is to use the recurrence of fire weather as measured by FFDI as the planning or design fire weather reference. The recurrence is determined by the applying the Generalised Extreme Value Analysis to local historical weather data of limited time period. The resultant distribution is fitted with an appropriate regression curve which allows the extrapolation beyond the available weather data recording period. The method is applied to a number of weather districts in the state of New South Wales of Australia. The derived FFDIs corresponding to the nominated recurrence is compared with the FFDIs based on traditional empirical methods.
\end{abstract}

KEYWORDS: wildfire, risk assessment, land-use planning, construction practice, fire weather, extreme value analysis, bushfire.

\section{NOMENCLATURE LISTING}

$\begin{array}{llll}\text { FFDI } & \text { Forest fire danger index } & \text { GFDI } & \text { Grassland fire danger index } \\ D & \text { Drought factor } & M & \text { Number of data collected } \\ H & \text { Relative humidity } & N & \text { Number of days since rain } \\ V & \text { Wind speed }(\mathrm{km} / \mathrm{hr})(\mathrm{10m}) & n & \text { Number of years of data } \\ T & \text { temperature }(\mathrm{C}) & m & \text { Rank value } \\ r^{2} & \text { Correlation coefficient } & R & \text { Return period or recurrence. } \\ \text { Extreme } & \text { Extreme Fire Danger Rating } & \text { extreme } & \text { Extreme value }\end{array}$

\section{INTRODUCTION}

Bushfires or wildland fires are a regular feature of the Australian landscape and of many parts of the world. They can be anticipated with some regularity although unlike floods and other natural hazards, have not been investigated for there annual probability of exceedance or annual return periods (recurrence). It is important that the likelihood of fire weather conditions and the severity of these conditions are identified for community preparedness during fire seasons. Various fire danger index systems in the form of nondimensional parameters have been introduced in various countries to provide measures of the fire weather extent [1]. In Australia, there are currently two index systems, namely the forest fire danger index (FFDI) and grassland fire danger index (GFDI) [2]. The associated fire danger rating systems, namely the forest fire danger rating and grassland fire danger rating (FFDR and GFDR) are used to guide suppression capability as well as to support fire warnings to communities. These index systems are also used as a basis of developing bushfire related land-use policies and standards for building construction [3, 4$]$.

Bushfires pose severe threats to life, property, and the environment in rural and urban interface areas [5, 6, 7]. Australia has ample examples of severe bushfire losses in the recent past. In the State of New South Wales (NSW), more than 200 residential houses were destroyed during the mid-December 1993 to January 1994 fires [8] and a total 109 residential houses were destroyed in the 2001/2002 bushfires [9]. In excess of 
500 houses were lost on 18 January 2003 bushfires in Canberra [10]. The Black Saturday fires in 2009 in the State of Victoria caused the losses of 173 lives and more than 2000 houses. The high severity and frequency of bushfire events have drawn increased attention from both government and the general public. As a result, a number of bushfire protection reforms have been made first in NSW and, in the wake of the Black Saturday fires, nationally [11, 12]. While many of these are known to have occurred during extreme weather events, not all adverse fire weather is associated with such losses. This may be due to a lack of ignition or rapid suppression by fire authorities. Notwithstanding, the likelihood of suitable conditions to propagate fire is a good indicator of a fire occurring [11].

Determining the severity of a potential bushfire for land-use planning and construction practice purposes is crucial in any planning assessment process $[9,13]$. Property protection measures are related to the concept of a 'design bushfire' [14]. Obtaining the correct inputs for developing the design bushfire is therefore critical in considering the protection of life and property assets, including resident and fire fighter safety, protection of homes and other infrastructure and the need to balance environmental objectives. In North America [15, 16] and in Australia [17] deterministic approaches to fire behavior are combined with fire engineering principles to determine defendable space for fire fighters and building protection.

In bushfire engineering, the design bushfire is dependent on weather and topographical conditions as well as the predominant vegetation class (fuel loads or structure) over which the fire burns [18]. In some cases designers may seek to develop alternate design fires as weather conditions may deviate from the presumed conditions based upon which, the deemed to satisfy provisions of the building code [19] were developed.

Attempts have been made in the past to quantify suitable design bushfires based on a frequency distribution profiles. Andrews et al. [20] considered the utilization of logistic regression and percentile analysis in describing severe weather. Blanchi et al [21] compared bushfire statistics in Australia from 1957 to 2009 with local meteorological conditions to determine conditions under which house loss was likely. They found little house loss below FFDI of 50. However, such approaches have limitations as they are based on the statistics of limited time period over which data is available. The datasets used in these approaches to determine the percentile or threshold values may result in underestimating the severity of potential regular fire weather conditions as extreme events may not have occurred within limited periods to represent local meteorological conditions. The concept of annual occurrence of exceedance (recurrence) for FFDI is used by the fire authority in the state of New South Wales (NSW), Australia, as a major input for determining the design bushfire conditions where an alternate method is proposed [3]. However, the foundation of the fire index data for the current nominated 1:50 recurrence was rather empirical and poorly quantified.

Extreme value statistical techniques are regularly used in determination of design conditions for protection against storm, flood and wind [23]. For example, the National Construction Code of Australia [19] uses the annual exceedance probabilities of extreme events to determine the importance level for structural design. However, little work has been produced for extreme fire weather. A preliminary attempt was made recently to demonstrate the application of extreme value analysis to enhancing defendable space for fire fighters and residents without clear explanation of the analysis and comparison with other established methods [14].

The current study aims to extend the extreme value analysis to an Australian bushfire (forest fire) indexing system for determining design conditions for bushfire protection. The approach is based on Generalised Extreme Value (GEV) analysis [22] to establish the annual exceedance probability or recurrence values of FFDI that can then be used for developing the design bushfire and construction requirements [4] as well as defendable space as part of an overall approach to bushfire protection. The GEV approach is also compared with the percentile value approach and the prescriptive settings adopted in NSW.

\section{RISK BASED DESIGN APPROACHES}

\section{FFDI and fire weather}

While it is clear that fire events are influenced by unusual or unpredictable weather conditions, the challenge is to ascertain likely (recurrent) scenarios for a geographical area, based on that area's own particular climatic characteristics. These scenarios have a major impact on policy direction on issues such as:-

- planning policy for future residential areas,

- the construction of buildings in bushfire prone areas, 
- the levels of hazard reduction needed to mitigate against the severity of events and assist with managing fire events, and

- risk assessment of existing areas, to ascertain likely vulnerabilities and corrective measures.

To best implement such processes, it is necessary to ensure accurate (or as accurate as can be expected) measurement of the major variables giving rise to bushfire events, that is the effect of fuel, weather and topography within a given geographical setting.

Fuels are assessed using a variety of techniques, and the assessment process needs to be relevant to the fire behaviour models applied. Current practice is to utilize surface fuels (with an elevated component) for rates of spread in the McArthur equations [24]. An additional component for canopy fuels is applied for total fuel to determine flame characteristics.

The more recent alternate model used by Project Vesta is believed to more accurately reflect rates of spread conditions in higher intensity fires, however the fuel assessment approach differs from McArthur approach as does the use of weather parameters in deriving fire behaviour including rates of spread and flame length [25]. To date, no one has been able to apply either of these models in the context of existing climatic conditions let alone for likely recurrence periods or under conditions of climate change.

As described above, the principle indicator of bushfire weather has been a non-dimensional index referred to as the FFDI or GFDI.

The FFDI generally describes the chances of a fire starting (if ignited), its behaviour and difficulty in suppression $[2,25]$. FFDI is calculated using the equations formulated by Noble et al [26] and is given by:

$$
\text { FFDI }=2 \exp (-0.450+0.987 \ln D-0.0345 H+0.0338 T+0.0234 V)
$$

where $D$ is drought factor, $H$ is relative humidity (\%), $V$ is wind speed $(\mathrm{kph})$ at $10 \mathrm{~m}$ reference height and $T$ is air temperature $\left({ }^{\circ} \mathrm{C}\right)$. The drought factor is derived from Keetch-Byram Drought Index or KBDI [27].

It can be seen that the exponential equation can give rise to dramatically increased indices with smal changes in reduced humidity and increased wind speed and/or temperature.

In context, while extensive work has been undertaken to relate bushfire risk to various fire danger index systems in Australia [28], Canada [29 - 30], USA [1] and Europe, mainly Greece, Italy [31], and Portugal [32], such indices appear useful in determining fire size and 'sustaining fire', but are of less relevant for determining likelihood of ignition [30].

\section{Use of FFDI in Bushfire Protection Design in Australia}

In Australia, FFDI has been recognized as most predictive of fire behavior including rate of spread at lower intensities though recent research suggests FFDI under predicts rates of spread at the higher range of FFDI [28]. In particular, the FFDI value of 12 is often used as a threshold below which hazard reduction burnings can be prescribed with safety [33].

NSW has led other States in the application of improved site assessment techniques for the planning of new urban areas within bushfire prone landscapes. Extensive research on house losses by CSIRO led to major recommendations on construction [7, 34]. In NSW, the focus turned to improved land use planning [35]. Early approaches had relied on fire intensity as a surrogate for bushfire attack [36]. In 2002, this was changed to the determination of radiant heat and flame length as a measure of direct bushfire attack. In 2006, this was further refined with the application of the 'view factor method' in determining radiant heat as an engineered solution [15]. The RFS acknowledged the relationship between land-use planning and construction with the release of Planning for Bush Fire Protection [3]. In 2009, the Australian Standard AS3959-2009 Construction in Bushfire Prone Areas [4] also adopted the NSW approach nationally, differentiating regional areas by FFDI. Each of these models, therefore, relied on the application of the McArthur equations [26] for fire behavior and determination of appropriate setbacks.

In each case, the application of fire weather data has been inferred rather than adequately assessed from past events and relied on assumed FFDI values. In some cases these have been supported by subsequent work [37] although only indirectly. 
In the past, the common approaches of fire authorities has been to consider the limited weather data available for a site and determine whether the policy decision for construction practice should be based on either the:

a) FFDI being exceeded on more than one occasion over the recent record available (about 30 years), which is assumed as the $1: 50$ year event $[3,4,38]$;

b) FFDI corresponding to a prescribed cumulative frequency percentile value of an available dataset [20]; or

c) derived FFDI from maximum values of wind speed, temperature, drought factor and minimum relative humidity for Extreme or Catastrophic Summer data [39].

The above approach has been used by AS3959-2009 based on advise from the vasrtious State fire authorities. Each of these methods has significant shortfalls and does not represent a valid approach to the assessment of fire weather. The first approach is based on recorded event data and observed FFDI within any period and, therefore, is rather empirical. It was also difficult to apply spot fire weather conditions across multiple fire weather districts. The second approach is also limited by a dataset which may not be long enough to include extreme observations. The final approach may provide a maximum potential but may result in unrealistic and excessively high design criteria since it is highly unlikely that all contributing parameters to FFDI as shown in Eq. (1) could attain the worst case values (so far as the FFDI is concerned) simultaneously at a given location.

These approaches have been used in the absence of a clear methodological and statistically appropriate approach to the determination of extreme events. It is also relevant to note that at the time of development of FFDI for planning and construction practice in NSW in 2005, the national fire weather dataset was not available to the fire service.

The major knowledge gap that has arisen is the true extent of future fire weather (or rather climate) on the pattern of house losses for the purposes of land-use planning and construction. The problem is one of defining the design fire based on climatic, topographic and vegetation/land-use data.

\section{Extreme Value Analysis for FFDI}

The use of the Generalised Extreme Value (GEV) approach is normally applied in relation to specific weather parameters such as temperature, wind speeds, rainfall, hail events, etc. It can be difficult to use the GEV distribution for individual parameters for fire weather as the extreme conditions may not apply when conditions are otherwise suitable for bushfire events. For example, wind speeds at the extreme are not associated with bushfire weather, but rather for cyclonic or other high wind or storm conditions. Drought may be associated with winter as well as summer conditions where temperatures are moderated.

The theoretical basis of GEV is covered elsewhere [23, 40, 41] but is seen by some [42] as being the preferred technique over other approaches. GEV Analysis provides a feasible tool for the determination of risk associated with the occurrence of these extreme weather conditions.

In general, it has been assumed that the use of a GEV analysis must utilize annual maximum values. The annual maximum approach can be substituted for a broader maximum values approach and applied where these values approach annual maximum.

The GEV analysis [42] can be briefly described in the following way. Assume that $M$ number of values of a given parameter, $y$, are available for $n$ years. The data points are ranked according to their values in a descending order. The return period or recurrence $R$ for the $m$ th ranked data point, $y_{m}$, is then evaluated from:

$R\left(y_{m}\right)=(n+1) / m$

The so obtained set of $M$ data pairs $\left(y_{m}, R_{m}\right)(m=1,2,3, \ldots, M)$ can be plotted on a log-linear graph. The resultant curve usually follows a log function of the form $[17,38,39]$

$y=a \ln R+b$

where $b$ is the intersect with the one year recurrence or return period. Eq. (3) can be used to extrapolate the return periods beyond the data period. 
The advantage of the GEV method over other methods discussed earlier is that it can be based on derived FFDI data for a locality or even only annual maxima. The greater the number of years of annual maximum data, the better the approximation of recurrence.

\section{DATA COLLECTION AND ANALYSIS}

\section{Data Collection}

Weather data was obtained from the national historical fire weather dataset [23] supplied by Sydney Region office of the Bureau of Meteorology (BOM). The data was originally presented in txt format and converted to EXCEL spreadsheet for analyzing. The dataset contains the following daily weather conditions for the period 1972-2009:

- daily 3:00 pm relative humidity (\%)

- daily 3:00 pm air temperature $\left({ }^{\circ} \mathrm{C}\right)$

- daily max air temperature $\left({ }^{\circ} \mathrm{C}\right)$

- daily 3:00 pm wind speed and direction (10 minute average)

- 24 hour rainfall (up to 9:00 am day prior)

- $\quad$ derived KBDI

- $\quad$ derived drought factor (DF) and

- $\quad$ derived maximum FFDI (and GFDI).

There are gaps in some of the datasets. Not all datasets have the complete list of parameters for the entire time period. For example, some FFDI values are missing due to missing information of drought factor, wind speed (and direction) or relative humidity. Some datasets may not extend back as far as 1972. These gaps are relatively few and do not affect the evaluation of recurrence. There are a range of anomalies that can occur due to temporal factors as well as instrumentation issues [23]. Another limitation of the dataset is the perceived maximum. The maximum FFDI for a given day may occur at times other than at 3:00 pm. Therefore, the 3:00 pm maximum may not accurately reflect the daily maximum FFDI. For consistency, the 3:00 pm data is used as a representation of maximum FFDI during that day. However, it also uses the daily maximum temperature which may be higher than the 3:00 pm temperature.

The State of NSW has 21 Fire Weather Districts [4] as shown in Fig. 1. Each weather district has multiple weather stations. However, not all weather stations have a complete dataset to calculate FFDI. Data from ten (10) NSW weather stations were used in the present study as they fall within areas of forest and/or woodland vegetation where FFDI is of greatest relevance. Other areas may be better associated with GFDI which are not included in the current study. The 10 weather stations and the fire weather districts in which they are located are approximated within Fig. 1. These locations and fire weather districts (district numbers) are:

- $\quad$ Sydney (Greater Sydney Fire Weather District)(4)

- $\quad$ Richmond (Greater Sydney Fire Weather District)(4)

- Williamtown (Greater Hunter Fire Weather District)(3)

- Coffs Harbour (North Coast Fire Weather District)(2)

- Casino (Far North Coast Fire Weather District)(1)

- Canberra (Australian Capital Territory)(8)

- Wagga Wagga (Eastern Riverina Fire Weather District)(17)

- Nowra (Illawarra/Shoalhaven Fire Weather District)(5)

- Dubbo (Lower Central West Plains Fire Weather District)(15)

- Moree (North-Western Fire Weather District)(13) 


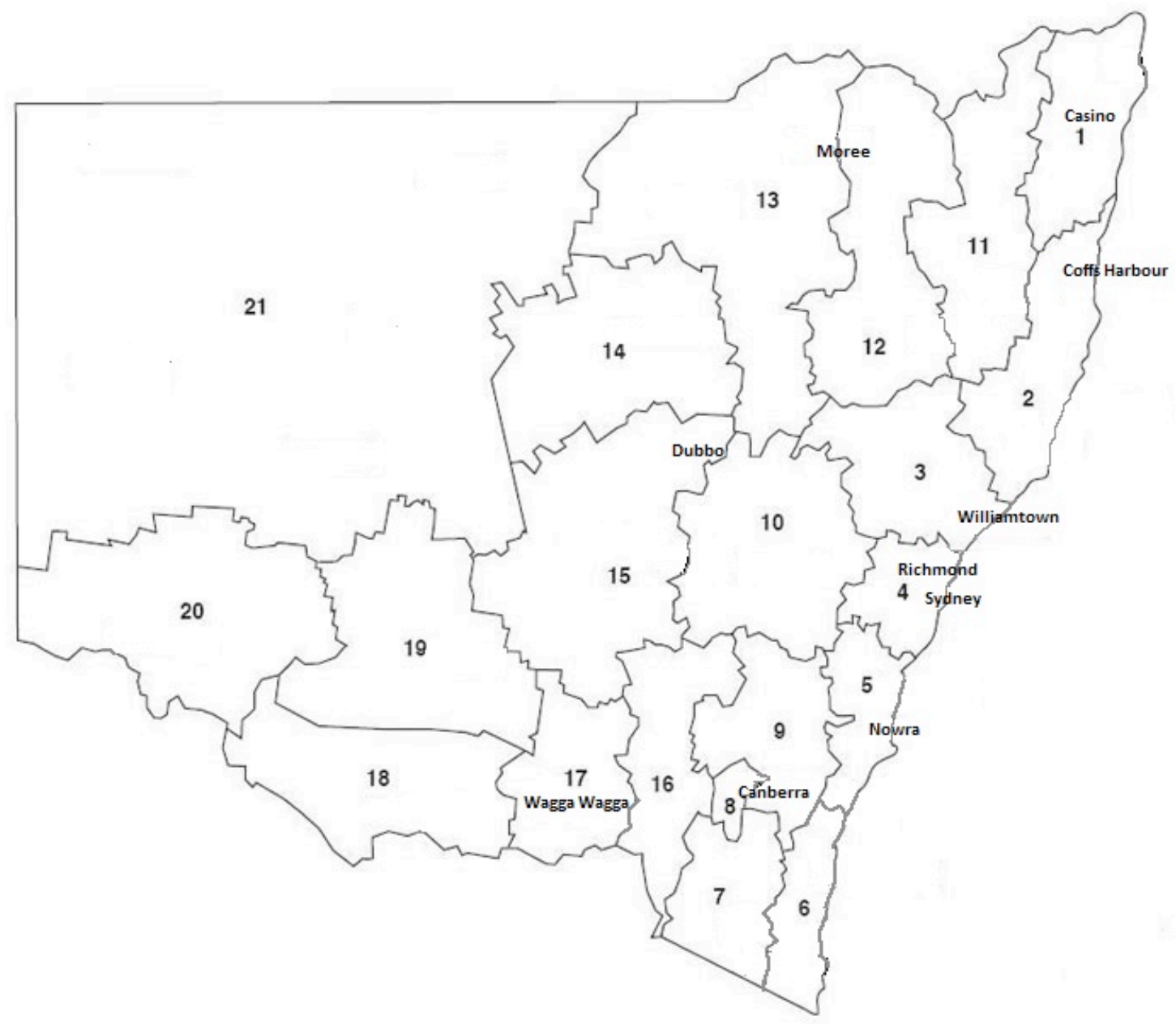

Fig. 1. NSW Fire Weather Districts [3] and approximate locations of weather stations used in the study.

\section{Percentile Analysis}

The obtained weather data was arranged in a spreadsheet to generate day and month, year and season columns to allow further analysis on different time intervals. Although the derived daily 3:00 pm FFDI is a surrogate for maximum daily FFDI and may not represent the actual maximum daily values, the 3:00pm FFDI using $T$ maximum is a good representation of the derived daily maximum FFDI. However, actual daily maximum FFDI's are still likely to be higher than that derived in the current study.

The southern hemisphere Summer is the season during which the annual maximum of FFDI and bushfires are most likely to occur. The current study, therefore, focused on the fire weather conditions during this season. Fig. 2 displays the Summer daily 3:00 pm FFDI data for Sydney weather station for the period 1972-2009 with a 90 day seasonal trend line. The Summer season in Sydney is taken from 1 December to the end of February. Some periodical or annual variations can be discerned though the overall variation in FFDI appears largely random. It is interesting to note that there seems to be a slight increasing trend in FFDI over the period studied. This trend is possibly attributable to climate change. However, definitive confirmation and attribution of this trend await further analysis which is beyond the scope of this paper.

Presented in Fig. 3 is the histogram of the data in Fig. 2. As can be seen in Fig. 3, the low FFDI events have relatively high frequencies than high FFDI events. The frequency almost decays exponentially with the increase in FFDI. This histogram is indicative of frequency distributions of FFDI data within the ten selected weather stations. Figure 4 illustrates the cumulative frequency distribution of summer 3:00pm FFDI data for Sydney airport. 


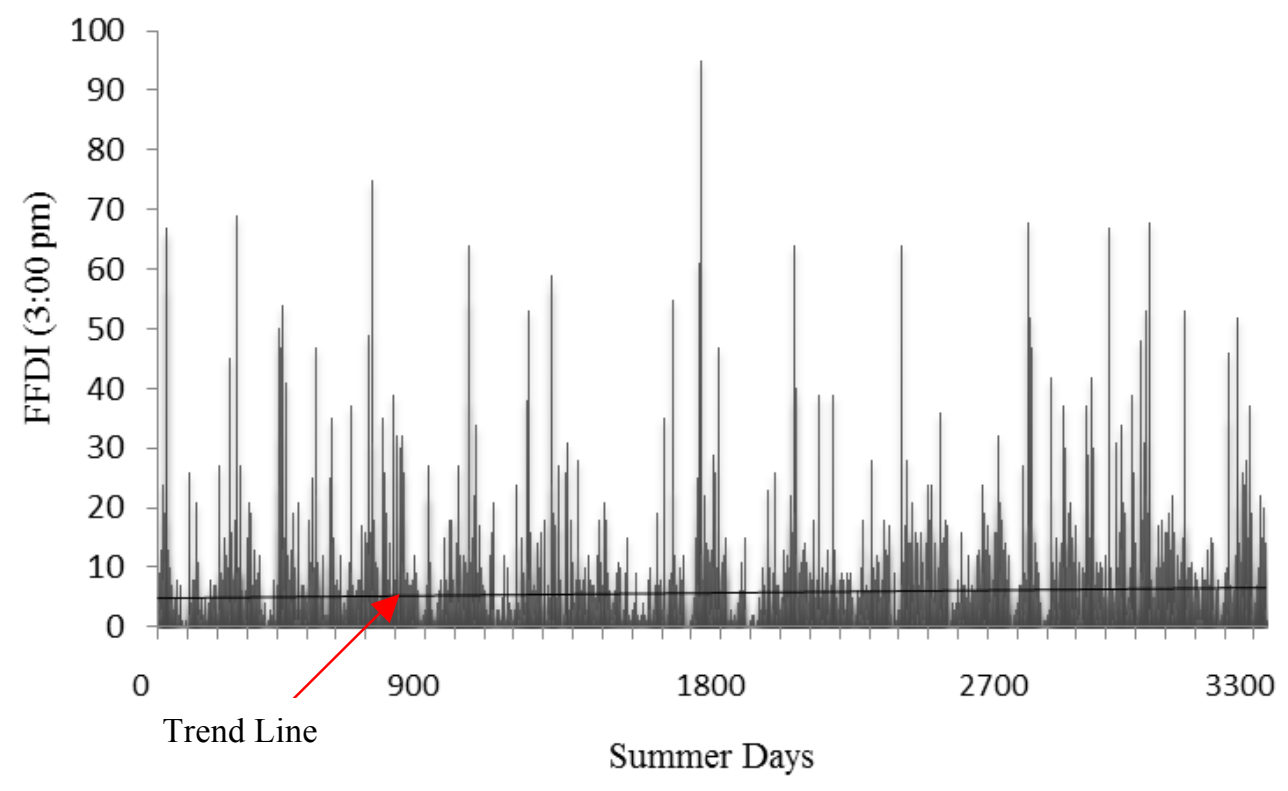

Fig 2. Summer daily 3:00pm FFDI for Sydney Airport Weather Station (1972-2009).

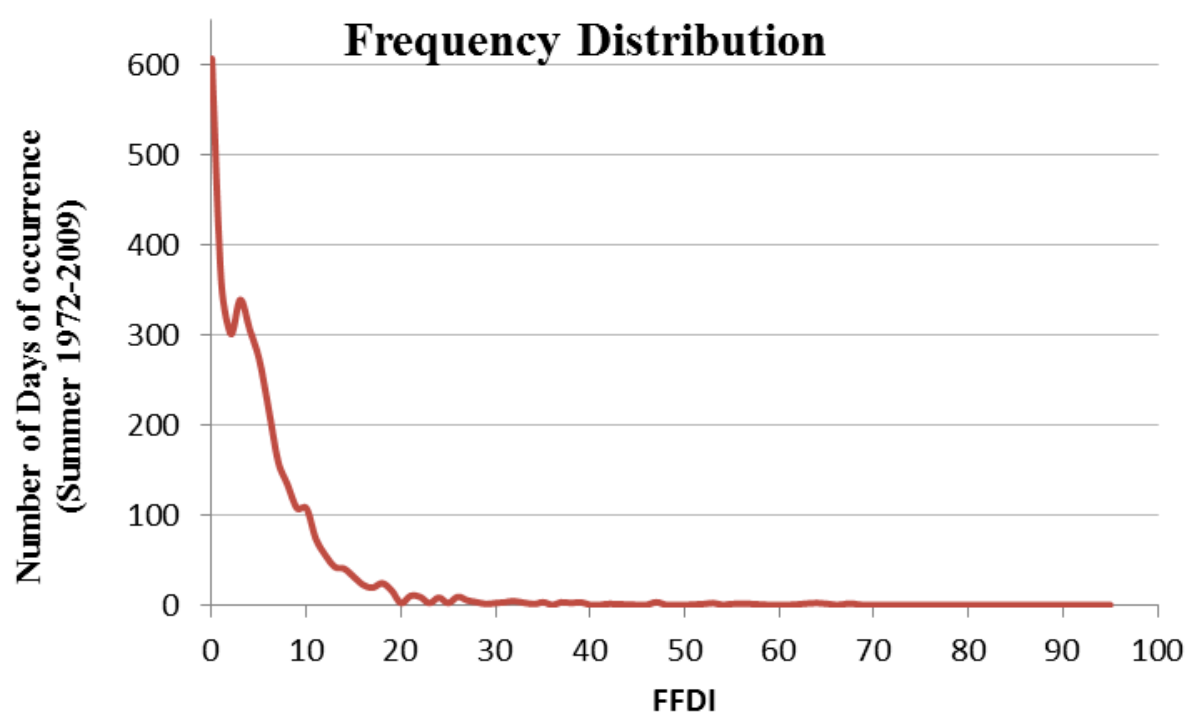

Fig. 3: Summer FFDI daily frequency distribution of Sydney Airport 3:00 pm, for period 1972-2009. (Courtesy of BoM, 2009)

A preliminary assessment of the data was undertaken for each weather station so as to ascertain Summer seasonal mean, 90, 95, 99 and 100 percentile FFDI values. The results are shown in Table 1. The table also includes the stated 'policy' FFDI values within AS3959-2009 for the fire weather districts in which the weather stations are located $[20,22]$.

As can be seen from Table 1, there is a significant gap between the 99 percentile value and the maximum FFDI at all stations, indicating that the events corresponding to the maximum FFDI are truly uncommon events. Together with Figs 3 and 4, it can be seen that the data is heavily 'biased' to lower FFDI values which can be regarded as noise when considering the application of GEV approaches [41]. Since the high frequency and low FFDI events or conditions are not of concern in risk based design or policy making, the noise can be ignored in GEV analysis. 


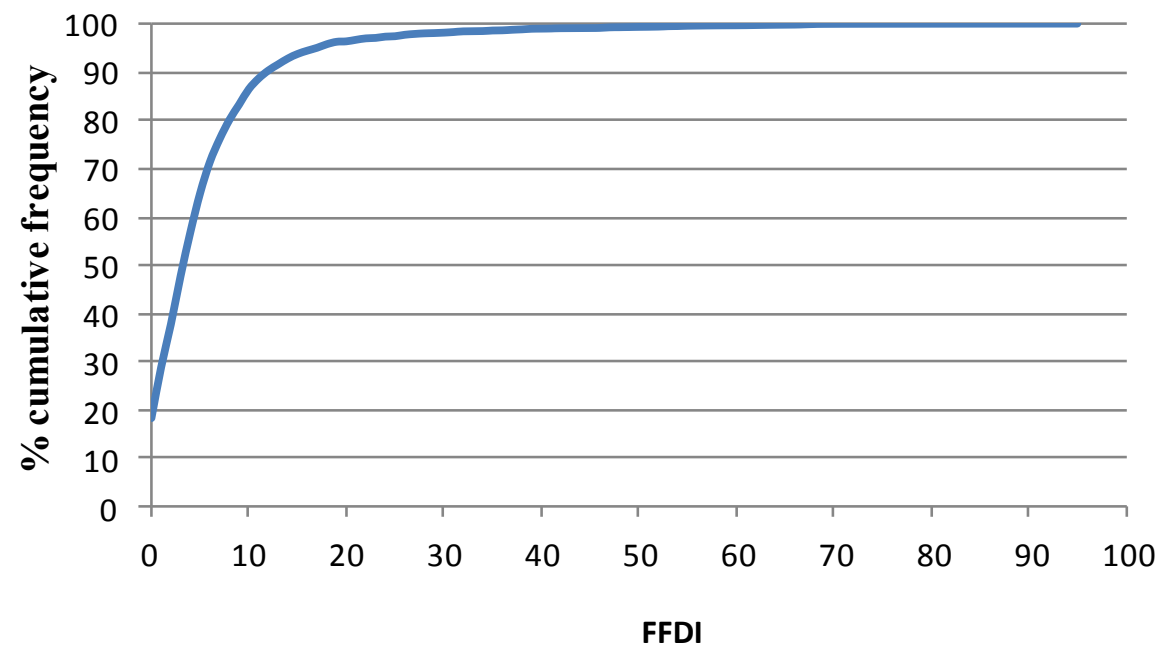

Fig. 4: Summer FFDI Cumulative Frequency Distribution at Sydney Airport 3:00pm for period 1972-2009. (Courtesy of BoM, 2009)

Table 1: Mean and percentile values for 3:00pm summer FFDI at 10 NSW weather stations (data generally from 1972-2009) compared to AS3959-2009 policy FFDI values.

\begin{tabular}{|l|c|c|c|c|c|c|}
\hline \multirow{2}{*}{ Weather Station } & \multicolumn{7}{|c|}{ FFDI } \\
\cline { 2 - 7 } & Mean & $\mathbf{9 0 \%}$ & $\mathbf{9 5 \%}$ & $\mathbf{9 9 \%}$ & $\mathbf{1 0 0 \%}$ (Max) & AS3959 \\
\hline Sydney & 5.7 & 12 & 17.7 & 41.3 & 95 & 100 \\
\hline Richmond & 8.1 & 21 & 28 & 45.2 & 96 & 100 \\
\hline Williamtown & 6.5 & 15 & 22 & 46 & 99 & 100 \\
\hline Coffs Harbour & 2.5 & 6 & 8 & 12 & 95 & 80 \\
\hline Casino & 4.8 & 11 & 15.4 & 30 & 101 & 80 \\
\hline Canberra & 11.7 & 27 & 34 & 51 & 99 & 100 \\
\hline Wagga Wagga & 18 & 36 & 45 & 65.4 & 138 & 80 \\
\hline Nowra & 5.3 & 11 & 19 & 46.8 & 120 & 100 \\
\hline Dubbo & 14 & 29 & 36 & 51 & 99 & 80 \\
\hline Moree & 15.5 & 28 & 34 & 46 & 125 & 80 \\
\hline
\end{tabular}

\section{Extreme Value Analysis and Comparison}

The 37 yearly highest FFDI values were used to generate GEV analysis of recurrence, or return period. Figures 5 and 6 provide examples of linear-log plots of FFDI $v s$ return period $R$ for Sydney and Richmond weather stations respectively, both of which are located within the Greater Sydney Fire Weather District [3]. The plots were then subject to a regression using the log-linear function as expressed in Eq. 3. The resultant lines of best fit are included in Figs 5 and 6 respectively. 


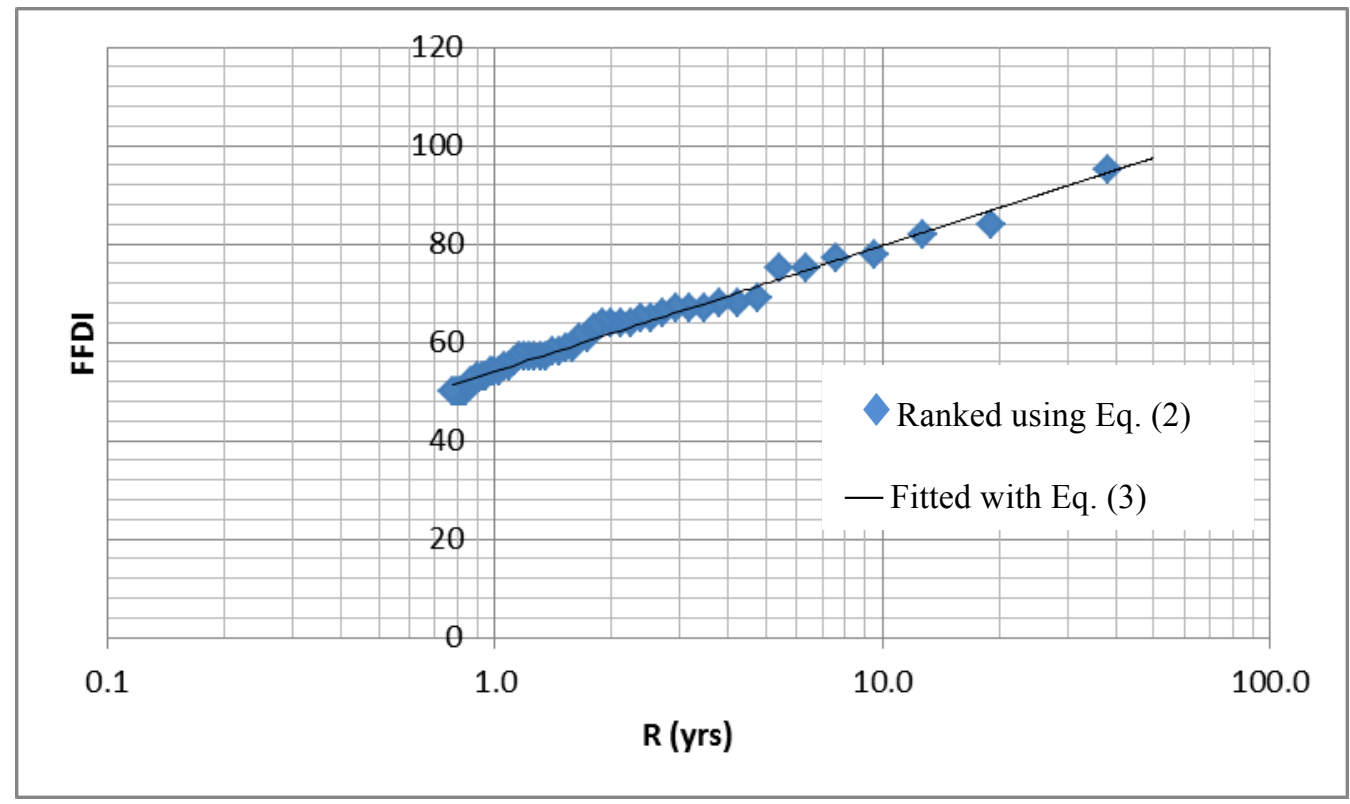

Fig. 5: Result of FFDI extreme value analysis and regression at Sydney Airport weather station.

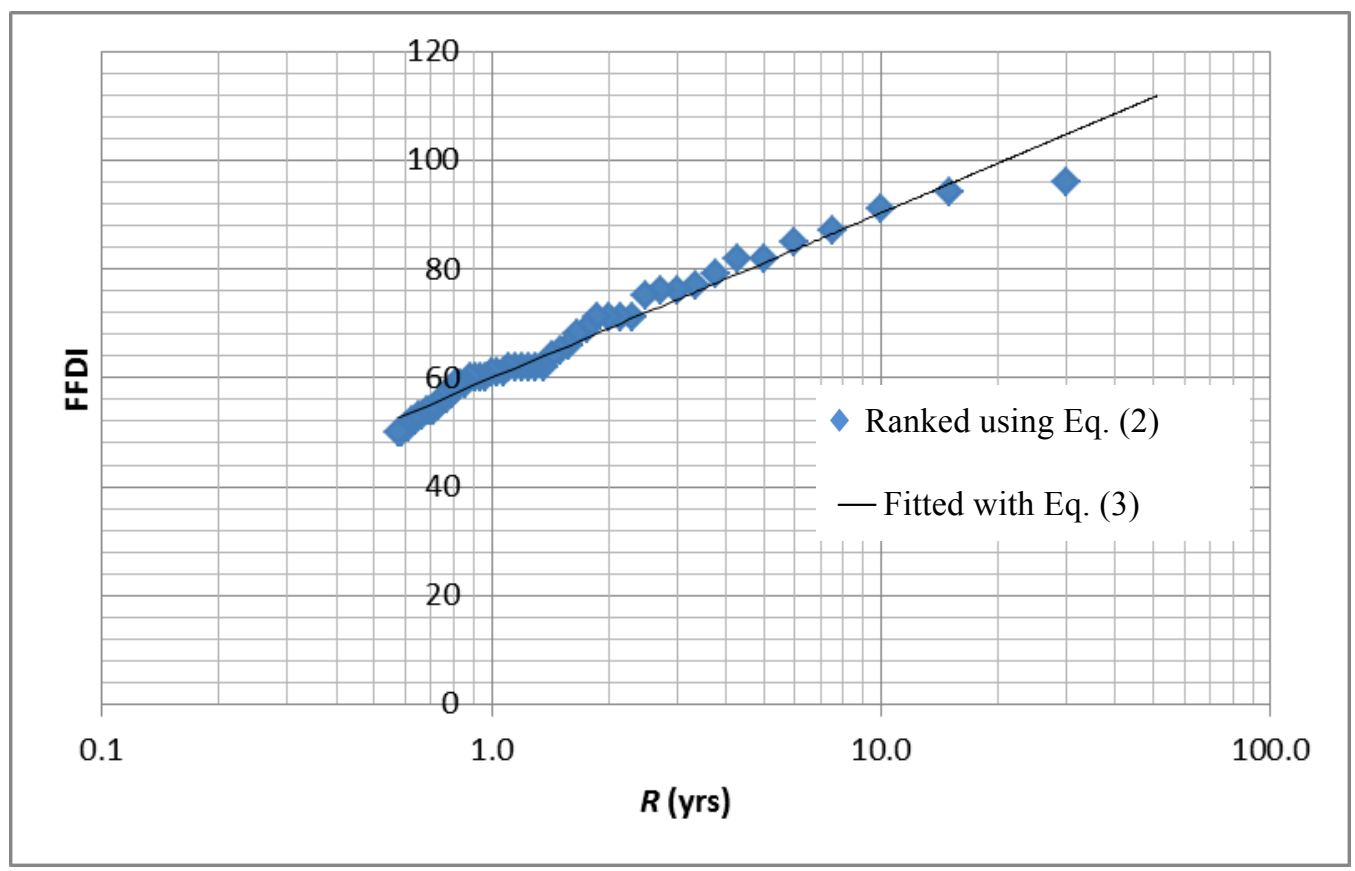

Fig. 6: Result of FFDI extreme value analysis and regression at Richmond Airport weather station.

The GEV and regression analyses were applied to all 10 selected weather stations and the results are presented in Table 2. Also included in Table 2 are the FFDI values corresponding to 1:50 and 1:100 return periods in comparison with the maximum FFDI obtained from the record and the policy FFDI values.

The regression line also corresponds to the theory of GEV assessment method as expressed in Eq. (3). The correlation co-efficient $r^{2}$ for each line of fit is very high, illustrating the good agreement between the theory and the obtained FFDI vs return period relationship. Therefore, the theory can be applied with a high level of confidence to obtain FFDI of return periods beyond the data collection period. 
Table 2: Result of GEV and regression analyses and comparison of FFDI values based on return periods, maximum and existing Australian Standard (AS3959-2009) for 10 weather districts.

\begin{tabular}{|l|c|c|c|c|c|c|c|}
\hline \multirow{2}{*}{ Station } & \multirow{2}{*}{$a$} & \multirow{2}{*}{$b$} & \multirow{2}{*}{$r^{2}$} & \multicolumn{4}{c|}{ FFDI } \\
\cline { 5 - 8 } & & & & $R=1: 50$ & $R=1: 100$ & Max & AS3959 \\
\hline Sydney Airport & 11.089 & 54.134 & 0.9842 & 98 & 105 & 95 & 100 \\
\hline Richmond & 13.196 & 59.913 & 0.9728 & 112 & 121 & 96 & 100 \\
\hline Williamtown & 13.227 & 54.672 & 0.9823 & 106 & 116 & 99 & 100 \\
\hline Coffs Harbour & 18.226 & 24.299 & 0.9722 & 96 & 108 & 95 & 80 \\
\hline Casino & 13.73 & 65.802 & 0.9424 & 120 & 129 & 101 & 80 \\
\hline Canberra & 12.212 & 51.752 & 0.9564 & 100 & 108 & 99 & 100 \\
\hline Wagga Wagga & 13.606 & 68.717 & 0.9753 & 122 & 131 & 138 & 80 \\
\hline Nowra & 15.973 & 49.854 & 0.9489 & 112 & 123 & 120 & 100 \\
\hline Dubbo & 13.156 & 55.728 & 0.9871 & 107 & 116 & 99 & 80 \\
\hline Moree & 16.937 & 48.961 & 0.9227 & 115 & 127 & 125 & 80 \\
\hline
\end{tabular}

The robustness of the approach can be seen in Table 2. For example, in some cases the 1:50 year event can be either noticeably higher or lower than the maximum recorded for the site. If the maximum recorded FFDI is used to develop a design bushfire, there is a chance that the resultant design fire may either under represent or over represent the fire intensity compared to the risk based reference design bushfire.

\section{DISCUSSION}

GEV analysis is a suitable method to determine recurrence (return periods) of FFDI. This method is preferred over traditional percentile analysis because of its robustness and ease in implementation.

Frequency distributed percentile values analysis is likely to underestimate fire weather conditions as part of the design bushfire. The maximum potential FFDI could either underestimate or overestimate fire weather conditions and is not suitable for establishing FFDI values for design bushfires.

The use of a 1:50 year return period is advocated by the NSW RFS [3] as the basis for determining fire weather conditions as an input to the development of an alternate method for the planning and construction of buildings in bushfire prone areas. GEV assessment of representative weather station data across all NSW fire weather districts would assist in a future review of FFDI for this purpose.

Although it would not necessarily hold true for all GEV assessments of the national fire weather dataset, the use of the ten weather stations in the current study indicates that the policy FFDI values established should be used as a minimum within the relevant fire weather districts and that in many cases would underestimate the potential impact of a 1:50 year fire event.

Of interest is that NSW North Coast values are significantly underestimated in terms of FFDI as part of the design bushfire. Casino, in particular could have a 1:50 year fire weather event larger than any recorded for 3:00 pm to date. In addition, fire weather districts further inland are also underestimated compared to the policy values for FFDI. Wagga Wagga, Dubbo and Moree all have significantly higher 1:50 year return periods than provided by current planning and construction practice (policy) using deemed to satisfy or acceptable solution approaches.

The Greater Sydney Region, Greater Hunter and ACT policy values compare well with the 1:50 year return periods, although it can be anticipated that areas of western and south-western Sydney could be slightly higher than current policy values. 
Correlation of regression lines for all stations is very high, indicating that the method is highly robust in the face of all the identified limitations of the dataset used. It also suggests that the current national fire weather and any future derived datasets developed in a similar manner can be used to represent FFDI return periods.

\section{CONCLUSION}

Bushfire behavior models require careful consideration of input parameters when addressing their application for land-use planning and construction practice. A review of previously applied approaches in Australia to determining FFDI for design bushfire purposes has identified their shortfalls. The derived maximum potential FFDI may overestimate the design FFDI leading to costly protection measures whereas in the cases of percentile analysis or multiple exceeding FFDI value approaches an underestimate of the design FFDI is more likely leading to unacceptable risk to life and property.

The well-established Generalised Extreme Value method has been extended in the current study to the determination of FFDI for design bushfire selection. This method has overcome the shortfalls of other existing methods. It is robust and does not necessarily require extensive period for data collection in order to establish a sound basis for determination of the design bushfire from fire weather data.

The application of this method to the selected datasets of 10 weather stations demonstrated good correlations between a logarithm regression model and the filed data. This result provides confidence for extrapolation of the model to obtain the desired or prescribed recurrence FFDI for risk based bushfire protection design. It can also be used to reflect an enhanced assessment of risk across the landscape for bushfire risk management planning.

With the availability of the Australian national fire weather dataset, it is now possible to scrutinize the data to obtain a more appropriate and robust assessment process using GEV methodology using FFDI. It is recommended that the GEV assessment should be applied to all data of the national fire weather dataset to provide input into the review of policy or prescribed FFDIs for planning and construction practice. In particular, the review of the bushfire construction standard AS3959-2009 provides an opportunity to revise FFDI as an input to the deemed to satisfy provisions of the National Construction Code. It is also feasible to apply GEV analysis of FFDI for the establishment of importance levels for bushfire protection, similar to structural load provisions of the National Construction Code.

GEV assessment approach may be applicable to other fire danger index systems such as those of Canada and USA.

The preliminary analysis of the forest fire danger index (FFDI) indicated a slight increasing trend in the recent 38 year period. This trend deserves careful attention as it may be attributed to climate change. If proven, it is highly likely that the fire danger index corresponding to a given recurrence will change with time and there may be major implications for climate change adaptation. While investigation of the impact on fire danger indices does not form part of the current study, work is being undertaken to determine if this can be better quantified on existing data.

\section{ACKNOWLEDGEMENTS}

The authors are indebted to the NSW Rural Fire Service for their support in the undertaking of this study. We would also like to thank Sydney Regional Office of the Bureau of Meteorology for making the various data available upon which this study is based. The support and the opportunities provided by the Bushfire Cooperative Research Centre are also acknowledged.

\section{REFERENCES}

[1] Hardy C.C. and Hardy C.E., (2007) Fire danger rating in the United States of America: an evolution since 1916, International Journal of Wildland Fire 16: 217-231, http://dx.doi.org/10.1071/WF06076.

[2] McArthur, A. G., Fire Behaviour in Eucalypt Forests, Forestry and Timber Bureau Leaflet 107, Commonwealth Department of National Development, Canberra, 1967, 36 p. 
[3] NSW Rural Fire Service, "Planning for bush fire protection - A guide for councils, planners, fire authorities and developers", 2006, Sydney, New South Wales.

[4] Standards Australia, “AS3959-2009: Construction in bushfire prone areas”, SAI Global, Sydney, 2009.

[5] Mell, W.E., Manzello, S.L., Maranghides, A., Butry, D. and Rehm, R.G., (2010) The wildlandurban interface fire problem - current approaches and research needs, International Journal of Wildland Fire, 19: 238-251, http://dx.doi.org/10.1071/WF07131.

[6] Massada, A.B., Radeloff, V.C. and Stewart, S.I., (2011) Allocating fuel breaks to optimally protect structures in the wildland-urban interface, International Journal of Wildland Fire, 20: 59-68, http://dx.doi.org/10.1071/WF09041.

[7] McFarlane, B.L., McGee, T.K. and Faulkner, H., (2011) Complexity of homeowner wildfire risk mitigation: an integration of hazard theories, International Journal of Wildland Fire, published online. http://dx.doi.org/10/1071/WF10096.

[8] Ramsay, G.C. and McArthur, N.A., "Building in the Urban Interface: Lessons from the January 1994 Sydney Bushfires,” Bushfire 1995, Australian Bushfire Conference, Hobart, Tasmania, 1995, pp 27-30.

[9] Douglas, G., Tan, Z. and Short, L., "NSW advances in approaching performance based assessments of residential developments in bushfire prone areas". Bushfire 2006 Conference, Brisbane, 6-9 June, 2006.

[10] McLeod, R., “The Inquiry into the Operational Response to the January 2003 bushfires", ACT Government, Canberra, ACT, 2005.

[11] Victorian Royal Commission into Bushfires (VBRC), "Summary Final Report", Melbourne, Victoria, 2010, $42 \mathrm{p}$.

[12] Keelty, M.J., “A Shared Responsibility: The Report of the Perth Hills Bushfire, February 2011 Review, Department of Premier and Cabinet West Australia, 2011.

[13] Douglas, G. and Ellis, P., "Integrating land-use planning and construction standards for protection for bushfires in NSW - a model", Bushfire 2001 Conference, May 2001, Christchurch, New Zealand.

[14] Douglas, G., "Using extreme value analysis to enhance Defendable Space for fire fighters and residents", Proceedings International Association of Wildland Fire Safety Summit, 2012, Sydney, Australia (In print).

[15] Butler, B.W. and Cohen, J.D., (1998) Firefighter safety zones: a theoretical model based on radiative heating, International Journal of Wildland Fire, 8(2): 73-77, http://dx.doi.org/10.1071/WF9980073.

[16] Cohen, J.D., (2004) Relating flame radiation to home ignition using modelling and experimental crown fires, Canadian Journal of Forest Research-Revue Canadienne de Recherché Forestiere 34(8); 1616-1626, http://dx.doi.org/10.1139/x04-049. 
[17] Douglas, G. and Tan, Z. "Integrating site assessment and performance planning outcomes for bushfire prone areas". Planning for natural hazards - how we can mitigate impacts? Symposium, University of Wollongong, 2-5 February 2005.

[18] Ramsay, G.C., Wynn-Jones, M., Wood, C., Douglas, G. and Robeson, P., "The Australian bushfire engineering guidelines", Proceedings of Fire Safety Engineering Conference, Society of Fire Safety, Gold Coast, Queensland, Australia, 2006.

[19] ABCB, National Construction Code, Building Code of Australia, Volume 1, Australian Building Codes Board, Canberra, ACT, 2013.

[20] Andrews, P.L., Loftsgaarden, D.O. and Bradshaw, L.S., (2003) Evaluation of fire danger rating indexes using logistic regression and percentile analysis, International Journal of Wildland Fire, 16(2): 174-182.

[21] Blanchii, R., Lucas, C., Leonard, J. and Finkele, K., (2010) Meteorological conditions and wildfire-related house loss in Australia, International Journal of Wildland Fire, 19; 914-926, http://dx.doi.org/10.1071/WF08175.

[22] Coles, S. An introduction to statistical modeling of extreme values. Springer-Verlag, London, 2004, $208 \mathrm{p}$.

[23] Lucas, C., (2010) On developing a historical fire weather dataset for Australia, Australian Journal of Meteorology and Oceanography, 60: 1-14.

[24] Gould, J., McCaw, W.L., Cheney, N.P., Ellis, P.F., Knight, I.K. and Sullivan, A.L., "Project Vesta- Fire in Dry Eucalypt Forest: Fuel structure, fuel dynamics and fire behavior". EnsisCSIRO, Canberra, ACT, and Department of Environment and Conservation, Perth WA, 2007.

[25] Verdon, D.C., Kiem, A.S. and Franks, S.W., (2004) Multi-decadal variability of forest fire risk eastern Australia, International Journal of Wildland Fire, 13(2): 165-171, http://dx.doi.org/10.1071/WF03034.

[26] Noble, I.R., Bary, G.A.V. and Gill, A.M. (1980) McArthur's fire danger meters expressed as equations, Australian Journal of Ecology, 5: 201-203, http://dx.doi.org/10.1111/j.14429993.1980.tb01243.x.

[27] Griffiths, D., (1999) Improved Formula for the Drought Factor in McArthur's Fire Danger Meter. Australian Forestry, 62(2): 202-206, http://dx.doi.org/10.1080/00049158.1999.10674783.

[28] Dowdy, A.J., Mills, G.A., Finkele, K. and de Groot, W., “Australian fire weather as represented by the McArthur Forest Fire Danger Index and the Canadian Forest Fire Weather Index", CAWCR Technical Report No. 10, CSIRO and Bureau of Meterology, , Canberra.

[29] Abbott, K.N., Leblon, B., Staples, G.C., McLean, D.A. and Alexander, M.E., (2007) Fire Danger Monitoring using RADASAT1 over Northern Boreal Forests, International Journal of Remote Sensing, 28(6):1317-1378, http://dx.doi.org/10.1080/01431160600904956.'

[30] Beverly, J.L. and Wotton, B.M., (2007). Modelling the probability of sustained flaming: predictive value of fire weather index components compared with observations of site weather and fuel 
moisture conditions, International Journal of Wildland Fire, 16 (2): 161-173, http://dx.doi.org/10.1071/WF06072.

[31] Good, P., Moriondo, M., Giannakopoulos, C. and Bindi, M., (2008) The meteorological conditions associated with extreme fire risk in Italy and Greece: relevance to climate model studies, International Journal of Wildland Fire, 17, 155-165, http://dx.doi.org/10.1071/WF07001.

[32] Fernandes, P.M., (2001) Fire spread prediction in shrub fuels in Portugal. Forest Ecology and Management, 144: 67-74, http://dx.doi.org/10.1016/S0378-1127(00)00363-7.

[33] NSW Rural Fire Service, Prescribed Burning S.O.P.S, (version 3) 2002.

[34] Ramsay, C.G., McArthur, N.A. and Dowling, V., (1987) Preliminary results from an examination of house survival in the 16 February 1983 bushfires in Australia, Fire and Materials, 11:49-51, http://dx.doi.org/10.1002/fam.810110105.

[35] Department of Planning, NSW Circular C10: Planning in Fire Prone Areas, Sydney, 1989.

[36] Department of Bush Fire Services, "Planning for Bush Fire Protection, A Guide for Councils, Planners, Fire Authorities, Developers and Home Owners (Draft)", Sydney, NSW, 1991.

[37] Hennessey, K., Lucas, C., Nicholls, N., Bathols, J., Suppiah, R. and Ricketts, J., “Climate Change impacts on fire-weather in south-east Australia", CSIRO, Victoria, 2005, 88 p.

[38] Douglas, G., "Report to the Country Fire Authority in relation to the implementation of defensible space and BAL levels for planning and building in WMO areas", University of Technology, Sydney,Sydney, NSW, 2011.

[39] Adrian, F., “AS 3959-2009 Forest Fire Danger Index (FFDI) Research Report (Draft Report)", Queensland Fire and Rescue Service, Rural Operations, Brisbane, QLD, 2009.

[40] Gumbel, E.J., Statistics of Extremes, Dover Publications, New York, USA, 2004.

[41] Reiss, R.D., Thomas, M., Statistical analysis of extreme values with applications to insurance, finance, hydrology and other fields, Birkenhauser, Third edition, Basel, Switzerland, 2007, 511 p.

[42] Makkonen, L., (2006) Plotting Positions in Extreme Value Analysis, Journal of Applied Meteorology and Climatology, 45: 334-340, http://dx.doi.org/10.1175/JAM2349.1. 